\title{
Presentación
}

\section{La memoria y sus relatos en Chile y América Latina. A cuarenta años del golpe de Estado del 11 de septiembre de 1973}

La conmemoración de los cuarenta años del golpe de Estado del 11 de septiembre en Chile, que acabó con el gobierno democrático de la Unidad Popular, liderado por el Dr. Salvador Allende Gossens, como había ocurrido ya con aniversarios previos, aunque cobrando en esta ocasión una intensidad particular, volvió a movilizar debates sociales y académicos en torno a la memoria y a la historia del pasado reciente de nuestro país. Por nuestra parte, desde el Centro de Estudios Culturales Latinoamericanos (CECLA) de la Universidad de Chile, decidimos tomar parte en esas discusiones, llevándolas a cabo desde el lugar de enunciación regional que nos caracteriza, y que nos insta a observar y comprender la realidad chilena a la luz del trasfondo mayor que ofrecen los procesos socio-políticos y culturales latinoamericanos.

En este marco, en mayo de 2013, realizamos en la Facultad de Filosofía y Humanidades, que alberga al CECLA, un seminario internacional titulado $A 40$ años del golpe de Estado en Chile. Desafíos y límites de los trabajos de la memoria en América Latina ${ }^{1}$, donde se dieron cita destacados especialistas con el fin de repensar estos temas, poniendo en diálogo visiones que abarcaban no solo distintas realidades históricas, sino también modos diversos de recordar y representar las herencias que aquellos procesos habían generado. Pues, en efecto, si bien la problemática de la memoria, sobre todo en el Cono Sur, suele aparecer asociada a las consecuencias del terrorismo de Estado impuesto por las dictaduras de las décadas de 1970 y 1980, al desplazar la vista en otras direcciones es posible distinguir memorias de otros conflictos sociales y políticos que, desplegados en otras zonas de América Latina, ofrecen espejos desde los cuales contrastar las

1 Este seminario y el presente número de Meridional se inscriben dentro del desarrollo de los proyectos Red Interdisciplinaria sobre Memoria Social-MINCYT Res. 547/13 (Argentina) y REDES 130057, DRI-CONICYT (Chile). 
propias historias y relatos, sean estos los oficiales o los eclipsados ${ }^{2}$. Asimismo, nos encontramos con memorias que involucran, no solo problemáticas políticas, sino también de etnia, raza, clase, género u otras; del mismo modo que surgen otras que dan cuenta de temporalidades diversas que, desbordando los límites de lo que podemos considerar el pasado reciente, involucran períodos más extensos e incluso centenarios, como sucede con las memorias de los tiempos coloniales y postcoloniales que, de distinto modo, se proyectan sobre nuestra contemporaneidad.

Bajo el mismo impulso que orientó el trabajo de este seminario, en el sentido de abrir las reflexiones sobre las memorias más allá de los marcos en que éstas habitualmente son situadas, el presente número de Meridional busca contribuir a esas discusiones que son locales pero también regionales y globales, mediante la publicación de siete artículos, a cargo de Werner Mackenbach, Jorge Montealegre, Alejandra Oberti, María Teresa Johansson y Constanza Vergara, Leonel Delgado, Manuel Guerrero e Idelber Avelar; textos que, desde distintas disciplinas, enfoques y estilos escriturales, trabajan con la memoria y sus representaciones, tanto en Chile como en la Argentina, Centroamérica, el Caribe y el Brasil. Por otra parte, es preciso destacar que, junto con los aportes que cada uno de estos textos entrega con relación a sus proposiciones específicas, ellos también incorporan cuestionamientos que intervienen críticamente las categorías desde las cuales se aborda el análisis de las memorias, ofreciendo nuevos e iluminadores modos de aproximarse a su estudio. Nos referimos, en particular, a las preguntas que instalan acerca de la memoria entendida como un campo de lucha ideológica acerca de las interpretaciones del pasado, sobre las posibilidades y límites del discurso testimonial, sobre los recursos que ofrecen la literatura y las prácticas artísticas y culturales en general para la representación de hechos y vivencias traumáticas, sobre los vínculos entre rememoración, subjetividad e identidad individual y colectiva, sobre la relación entre el presente, el pasado y los proyectos de futuro, entre varias otras.

Este número temático de Meridional se complementa, asimismo, con una sección que hemos denominado Testimonios y reflexiones, donde incluimos

2 Sobre la noción de memorias ocultas o eclipsadas, como prefiere denominarlas el autor, cfr. Jorge Montealegre, Memorias eclipsadas. Duelo y resiliencia en la prisión política. Santiago de Chile: Asterion, 2013. 
dos textos de autores chilenos, Bernardo Subercaseaux y Camila Bunster, los que desde discursividades autobiográficas que ponen en escena un yo personal, dan cuenta de experiencias que tienen como centro el impacto que el golpe de Estado y los casi dieciocho años de dictadura tuvieron en sus vidas y en las de sus familias. En el primer caso, lo que se recupera es la perspectiva de una persona que integró la generación de jóvenes intelectuales que, desde la mañana del 11 de septiembre de 1973, debió sufrir la dura prueba de la represión dictatorial y, peor aún, vivenciarla dentro de una institución, como la Universidad de Chile, que desde su fundación en el siglo XIX había encarnado los más altos ideales republicanos. En el segundo testimonio, por su parte, lo que emerge es la vOz de una joven nacida en Dinamarca, hija de un miembro activo de la resistencia antidictatorial y de una madre danesa solidaria con esas luchas, quien expone en la escritura las tensiones de una subjetividad escindida entre dos países, dos lenguas y dos linajes, describiéndose a sí misma como un ser con un "corazón irremediablemente partido". Junto con los siete artículos anteriormente presentados, de índole eminentemente analítica, estos textos testimoniales, donde también está presente la reflexividad crítica, restituyen una dimensión subjetiva que estimamos esencial en una publicación dedicada a la memoria y sus relatos; por eso mismo, decidimos que ellos no podían estar ausentes en una compilación como la que aquí presentamos.

Según decíamos en un comienzo, la conmemoración de los cuarenta años del golpe de Estado en Chile fue un impulso que, tanto a nivel social como académico, permitió volver la mirada a esta historia inconclusa que se inicia con la irrupción militar, sobre la que, pese al tiempo transcurrido, aun se ha hablado poco y respecto de la cual todavía quedan muchos vacíos y preguntas abiertas. Estamos, sin duda, ante una discusión de relevancia que esperamos que no quede clausurada con el término de este aniversario, pues resulta fundamental para afirmar un futuro democrático que solo podrá consolidarse sobre la base de la memoria, entendida como una praxis crítica respecto del pasado, así como de la verdad y la justicia acerca de los hechos trágicos acontecidos en Chile a partir de 1973. Por nuestra parte, solo esperamos que los trabajos incluidos en este segundo número de Meridional colaboren a ese fin, manteniendo vivo el interés en el tema y promoviendo nuevas y productivas indagaciones.

Alicia N. Salomone 